\title{
When And Why Does The That's-Not-All Compliance Technique Work?
}

\author{
Yun-Oh Whang, Ph.D., University of Tampa, USA
}

\begin{abstract}
The paper examines the underlying theoretical explanation for a common persuasion technique commonly used in marketing called 'that's-not-all' (TNA). The TNA technique is a communication method where a sales pitch is followed by a bonus offer with a time delay, which is more effective than presenting the main item and the bonus simultaneously. Previous research in psychology proposed two competing explanations for its effectiveness-norm of reciprocity and the anchor adjustment heuristic - with mixed results. To test these competing explanations for the TNA technique, a 2x2 factorial experiment is designed with the use of TNA and the net attractiveness of the deal as independent variables. The result found norm of reciprocity as the dominant cognitive process behind the technique, while anchor adjustment heuristic failed to explain the effectiveness of the technique. It also provides an important marketing implication that TNA can be effective only when the net value of the deal including both the main and bonus items is below the reservation price of the consumers.
\end{abstract}

Keywords: Compliance; Norm of Reciprocity; Anchor Adjustment Heuristic

\section{INTRODUCTION}

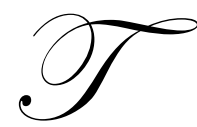

wo major communication strategies have been of interest in both marketing and psychology. One focuses on persuasion that influences cognitive or attitudinal precursors of behavior, and the other focuses on direct modification of behavior (Tybout 1978). Since it is widely known that attitude is not a perfect predictor of behavior, several direct influence strategies have been studied.

Fraser (1966) initiated this area of research by asking 'how a person can be induced to do something he would rather not do.' Since then, more than 50 studies have been published in both marketing and psychology to find the answer, mainly using two major compliance techniques; 'foot-in-the-door' (hereafter FITD) and 'door-inthe-face' (hereafter DITF) (see Dillards 1991, Fennis and Janssen 2010, Fern, Monroe, and Avila 1986, and Mowen and Cialdini 1980 for reviews). FITD procedure uses a small initial request with high probability of compliance followed by a larger main request of interest. DITF starts with a large initial request followed by a relatively smaller request after the receiver rejects the initial request. These techniques have been widely studied and used by recruiters, salespersons, and con artists for many years (Cialdini 1984).

However, another compliance technique called 'that's-not-all' (hereafter TNA) is apparently more widely practiced in marketing context, but it has not been in the spotlight. TNA is a technique where a request is made and an additional discount or bonus item is offered later without allowing the recipient to accept/reject the initial offer. For example, a salesperson introduces a product to a customer with its features and price. A few seconds later, he says "that's not all," and offers an additional incentive. The applications of TNA technique can be easily found in TV commercials where the main product is introduced first and additional bonus items are presented later using a 'special limited time offer' or 'if you call now' format.

TNA compliance technique is believed in marketing practice to be more effective than presenting the whole deal together. Salespeople often apply this technique to generate more sales, and Home Shopping Network always starts with a higher price and lowers it to the actual price later. However, it has not been well understood why and when TNA works. Burger (1986) is the only study that investigated the effectiveness of TNA with a series of 
controlled experiments. However, the mixed results failed to provide a clear theoretical explanation for the process.

In this paper, the effectiveness of TNA is examined with a set of competing hypotheses developed to identify the underlying cognitive process, and a single experiment is designed to test both competing hypotheses simultaneously. The conceptual framework and hypotheses are presented in the next section, followed by the experiment designed to test the hypotheses. The results are reported in the next section, and general discussion and concluding remarks are presented in the last section.

\section{CONCEPTUAL FRAMEWORK}

\section{Norm of Reciprocity}

There are two potential theoretical explanations for the effectiveness of TNA. First, the norm of reciprocity (Gouldner 1960; Burger 1986) is one of the widely accepted theories behind the technique. This theory has also been the main explanation for DITF technique, where the relatively small subsequent request is perceived as a concession by the requester from the large initial request (Cialdini et al. 1975; Regan 1971). The receiver feels that he has to return the favor by complying with the second request. Since TNA technique also adds more incentive by offering a further price discount or bonus items, it can be perceived as a bargain-concession process. The recipient is likely to feel obligated to meet the requester halfway by complying with the combined offer after being presented with the price discount or bonus items.

For example, suppose a consumer visits an electronic appliance store to buy a television. A salesperson approaches the consumer and introduces a new brand of TV with a $\$ 200$ price tag. A few seconds later, the salesperson says that he can offer a DVD of the consumer's choice as a bonus because he is behind his quota of the week. The consumer would perceive the DVD offer as receiving a favor from the salesperson, and is more likely to accept the whole deal. On the other hand, when the consumer is presented with the TV and the DVD offer at the same time, the consumer is less likely to perceive it as receiving a favor because it seems that the video offer is not only for him.

\section{Anchor Adjustment Heuristic}

The second explanation is the anchor adjustment heuristic based on adaptation level theory (Helson 1964). It suggests that attitudinal judgment has to be considered within the particular frame of reference of the individual making the judgment (Sherif and Sherif 1967). The frame of reference serves as an anchor point against which a new object is assessed. It has been reported that the anchor point can be altered through various experiences (e.g., Brickman, Coates, and Janoff-Bulman 1978; Kenrick and Gutierres 1980; Manis and Moore 1978; Pepitone and DiNubile 1976). Therefore, the receiver could shift the anchor when the initial request is made, and the net offer including the additional offer becomes more attractive because the anchor for the net deal has shifted.

For example, when a consumer who has an anchor of $\$ 4.50$ for a box of cereal is offered a price of $\$ 5.50$, the anchor point moves closer to $\$ 5.50$. When the consumer is offered a $\$ 1.00$ discount, he is more likely to buy the cereal than when he is presented with a $\$ 5.50$ price tag and the discount at the same time. If the two offers are presented at the same time, the anchor point does not shift because the consumer does not process the initial price tag separately. Instead, the consumer processes the deal by calculating the net offer $(\$ 4.50=\$ 5.50-\$ 1.00)$ before triggering the judgment process.

\section{Applying The Explanations in Marketing Contexts}

Both explanations seem plausible and were partially supported by Burger (1986), but neither was clearly supported. His conclusion was that norm of reciprocity was not able to solely explain the effectiveness of TNA technique. Examining his experimental settings, the main problem with the series of experiments conducted is that each experiment was designed to test only one explanation at a time. However, his experimental design tested each hypothesis separately, while it is probable both processes work simultaneously. Thus, the key to explaining the cognitive process behind TNA is to find the dominant process. 
However, in the context of marketing, the anchor adjustment heuristic explanation seems to be problematic. Berger used cupcakes and candles as the products on sale in his experiments. Consumers usually have ambiguous price perception for these products because of their wide variation in quality and infrequent purchase occasions. This implies their anchor prices can shift relatively easily. However, consumers generally have a fairly rigid price in mind for certain product categories. For example, when men talk about how much they paid for new televisions, they often express immediate responses of either 'you paid too much' or 'you got a pretty good deal'.

Here we introduce the notion of reservation price. Reservation price is defined as the price a consumer is willing to pay for a product, and it is often used anchor point when consumers make purchase decisions. For most product categories the reservation prices are quite solid, as shown in the television example mentioned above. In other words, it is hard to shift the reservation price for certain products. As a result, it would be difficult to explain the effectiveness of TNA technique with anchor adjustment heuristic for those products for which consumers have clear reservation price as a price anchor. Therefore, if we test these hypotheses in a marketing context using a product category with solid reservation prices, we can test if the norm of reciprocity hypothesis is indeed behind TNA process.

\section{EMPIRICAL TEST}

The experiment tests the effectiveness of the TNA technique with the hypotheses presented above. It has a $2 \times 2$ factorial design with one dimension being whether TNA technique is used or not, and the other dimension being the attractiveness of the net deal (see Figure 1).

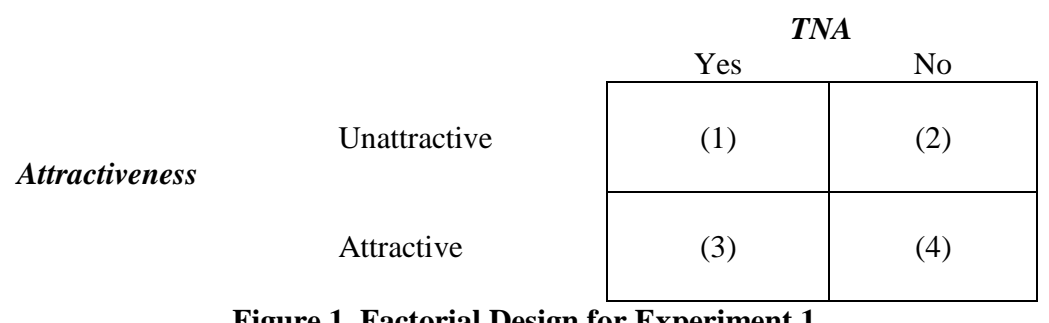

Figure 1. Factorial Design for Experiment 1

\section{Hypotheses}

It has already been reported that TNA technique is more effective in terms of inducing compliance than presenting both offers at the same time (Burger 1986). Both hypotheses predict this result, which is why the purchase intentions in cells 1 and 3 are expected to be higher than in cells 3 and 4, predicting a main effect of TNA vs. non-TNA.

However, the main focus of this experiment is on the attractiveness dimension. There are two offers made (initial and bonus offers) and the net worth of the whole deal is of interest. For example, when a salesperson presents a new brand of TV with a $\$ 500$ price tag, and later offers (in TNA condition) a bonus DVD movie worth $\$ 20$, the net worth of the whole deal is $\$ 480$. In other words, the net worth of the deal is the monetary value the consumer receives.

The attractiveness conditions are defined as whether the net worth of the deal is above (unattractive condition) or below (attractive condition) the reservation price. Without sequential offers, rational consumers only accept offers when net price is less than reservation price. Therefore, there is no reason to employ TNA if the initial offer has a lower price than the reservation price because the consumer is already willing to accept the offer. Obviously, marketers would consider using TNA and prepare additional incentives (second offer) when they know that consumers would hesitate to accept the initial offer. In other words, TNA technique should be used only when the initial offer is not attractive. Thus, we will not consider the case where initial offer is less than reservation price. From now on, we will not consider the case where the initial offer has lower price tag than the reservation price. 
In summary, the manipulation of the attractiveness conditions is not based on the initial offer. The criterion is whether the net worth is greater than (attractive) or less than (unattractive) the reservation price. For example, suppose a consumer is in the market for a TV. His reservation price for a 27 -inch TV is $\$ 200$. When he sees a price tag of $\$ 220$ at a store, he would be reluctant to accept the offer. If the consumer is presented with a second offer that is worth $\$ 10$, the net worth becomes $\$ 210$, which is still higher than the reservation price. We call this condition the 'unattractive' condition. On the other hand, the consumer could receive a second offer worth $\$ 30$. The net worth in this case becomes $\$ 190$, and it is below the reservation price. This condition is called 'attractive.' Note that the initial offer is always unattractive, and the value of the bonus offer either keeps it unattractive or turns it to an attractive net offer.

\section{Predictions by The Norm of Reciprocity Explanation}

The advantage of including the attractiveness dimension in the experimental design is to differentiate the impacts of norm of reciprocity and anchor adjustment heuristic in a single experiment. First, assume that the net offer has less monetary value than the reservation price. After receiving the initial unattractive offer, the consumer tries to attribute the discrepancy to some other characteristics of the product such as quality. The role of price as a quality signal has been reported in marketing literature (e.g., Dawar and Parker 1994), and the consumer is likely to think that the presented product has higher quality than his standard. The reservation price does not have to shift in this attribution process since the consumer has a certain level of quality attached to his reservation price.

When this consumer later receives the second offer that makes the net worth still unattractive, the attribution of higher price to higher quality remains because the second offer only reduced the magnitude of the discrepancy but not the direction. If the norm of reciprocity works, the consumer perceives the second offer as receiving a favor and is more likely to accept the offer even though the net worth is still unattractive. The consumer does not reevaluate the whole deal because the second offer does not change the nature of the unattractive deal. Therefore, there is no barrier for the second offer to be perceived as a favor.

However, if the second offer makes the whole deal attractive, this may confuse the consumer, and he may perceive the offer as 'too good to be true'. In addition, the credibility of the salesperson becomes questionable because the consumer imagines the consequence had he accepted the initial offer and did not receive the second offer. Due to these inconsistencies, the whole deal is likely to be reevaluated by the consumer, and it is less likely that the second offer is perceived as a favor. Furthermore, the negative affective state due to confusion and doubtful source credibility may affect the overall product evaluation (Isen and Shalker 1982) and eventually move the consumer away from accepting the deal.

In short, the norm of reciprocity explanation predicts that TNA technique works better when the net worth is unattractive. The hypothesis summarizing the prediction is stated below.

$\mathbf{H}_{1}$ : $\quad$ TNA technique induces relatively higher purchase intention than without using the TNA technique when the net worth of the offer is not attractive.

In Figure 1, the hypothesis implies that the increase in purchase intention from cell 2 to cell 1 is higher than the increase from cell 4 to 3 .

\section{Predictions by The Anchor Adjustment Heuristic Explanation}

The $\mathrm{H}_{1}$ developed above is based on the assumption that reservation price does not shift even when evaluating a product with a higher price. As mentioned earlier, this assumption is realistic in marketing context because consumers have pretty good idea about the reasonable price level for certain product categories.

However, it is still possible that the anchor point shifts and the move generates higher purchase intention in TNA conditions. Suppose anchoring explains the effectiveness of TNA. Anchor adjustment heuristic predicts that the anchor point shifts closer toward the actual price when a price higher than the reservation price is presented. In the example used earlier, the consumer may shift the reservation price upward from $\$ 200$ when he finds out the 
actual price at the store is $\$ 220$. The reservation price would not go up all the way to $\$ 220$, but it increases to between $\$ 200$ and $\$ 220$. In this case, the amount of the bonus offer determines the purchase intention under TNA. In other words, a $\$ 30$ coupon for a DVD movie is more attractive than a $\$ 10$ offer because the greater the bonus offer's monetary value, the more likely it is that the net offer's value falls below the newly adjusted reservation price.

Therefore, anchor adjustment heuristic predicts that the purchase intention under TNA is higher when the bonus offer is more attractive regardless of the net worth of the whole deal. This means that in Figure 1 the increased purchase intention from cell 4 to 3 is higher than the increase from cell 2 to 1 , which is the opposite of $\mathrm{H}_{1}$. The hypothesis stated below summarizes the prediction.

$\mathbf{H}_{2}$ : TNA technique is more effective than non-TNA condition when the second offer has higher value regardless of the net worth of the deal.

In short, hypotheses 1 and 2 represent the interaction effect between TNA and the attractiveness of the net worth, and the two theoretical explanations make incompatible predictions. Thus, we can determine which theory better explains the effectiveness of TNA in marketing context.

\section{Procedure}

The subjects were recruited from the business school of a Midwestern university. They were asked to participate in a computer simulation of a purchase decision making task. They were first asked to fill out a specification sheet online for a 27-inch LCD TV that fits their needs, and at the end they were asked how much they were willing to pay for the product. Since the reservation price of each individual varies, it is difficult to control whether the net worth of the deal falls below or above the reservation price. Therefore, we used the reservation price given by the subjects in this first step to automatically generate the condition where the net worth is either above or below the provided reservation price.

Then the subjects were presented with a fictitious brand of LCD TV to be introduced to market soon. The presentation resembled an email sent by a salesperson. The subjects in the TNA condition were offered a price slightly higher than their reservation price. Fifteen seconds after the initial offer on a 27 -inch TV, the second offer of a bonus DVD showed up in a separate email. The subjects in the non-TNA condition were presented with the information on the TV and bonus DVD together in one email. Since, consumers generally perceive price differences in percentage rather than absolute terms, the initial and bonus offers were computed based on the reservation price given by the subjects using a constant percentage formula. For example, for a subject who reported $\$ 200$ as his reservation price for the $\mathrm{TV}$, the simulation program generated a price of $\$ 220$ (10\% higher than the self-reported reservation price). Additionally, the attractive condition offered a bonus DVD worth $15 \%$ of the reservation price (\$33) resulting in a net worth of $\$ 187$ and the unattractive condition offered a bonus DVD worth 5\% (\$11) resulting in a net worth of \$209. The subjects' purchased intention was surveyed using a 7-point Likert scale after examining the product information.

\section{Results and Discussion}

The results are summarized in Table 1 and Figure 2. The purchase intentions show significant increase from non-TNA to TNA conditions as a main effect $(t=2.289, p<0.05)$. It was mainly contributed by the difference in the unattractive condition where the mean value for purchase intention jumped from 3.92 (non-TNA) to 5.00 (TNA). On the other hand, the TNA condition (4.82) failed to show a significant difference from the non-TNA condition (4.77) when the net worth is attractive. This interaction effect was significant $(F=5.862, p<0.05)$, which supports the norm of reciprocity hypothesis $\left(\mathrm{H}_{1}\right)$, and therefore, the anchoring hypothesis $\left(\mathrm{H}_{2}\right)$ is not supported. This implies that the reservation prices of the subjects did not shift due to processing the initial offer of a higher price. 
Table 1. Purchase Intention Averages

\begin{tabular}{|l|c|c|}
\hline & TNA & Non-TNA \\
\hline Unattractive & 5.00 & 3.92 \\
\hline Attractive & 4.82 & 4.77 \\
\hline
\end{tabular}

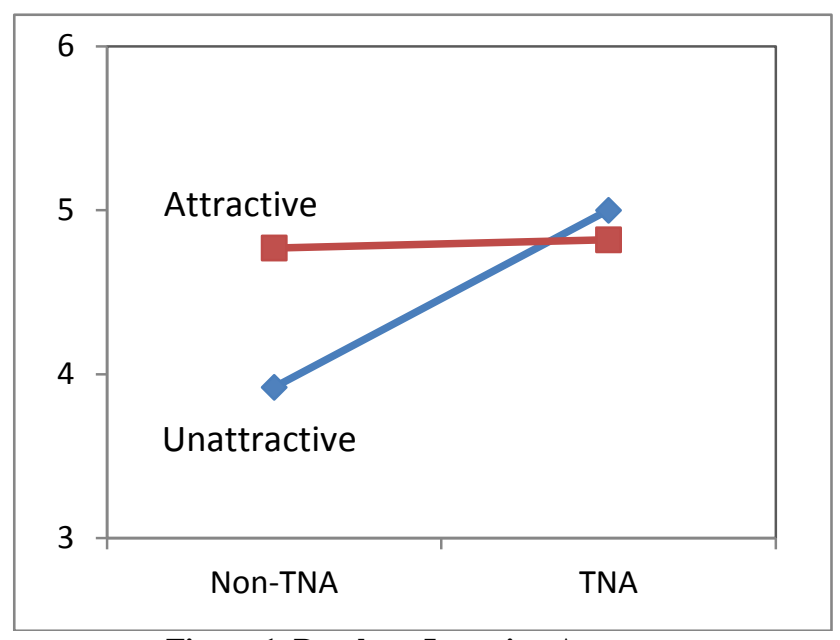

Figure 1. Purchase Intention Averages

It should also be noted that the purchase intention in the unattractive condition is higher than the attractive condition when TNA technique was used even though the difference is not significant. As discussed earlier when formulating $\mathrm{H}_{1}$, the confusion by the consumers when the net worth becomes attractive after the bonus offer seems to play a role here. It is counterintuitive that an attractive deal is rated with less purchase intention. However, flipping of deal that went from unattractive (initial offer) to attractive (net worth) apparently made it more difficult for the subjects to make a purchase decision.

\section{GENERAL DISCUSSION AND CONCLUDING REMARKS}

The finding presented in the previous section indicates that norm of reciprocity better explains the cognitive process underlying TNA. Even if net worth remains unattractive, TNA increases purchase intention due to the consumer's desire to reciprocate the bonus offer.

One possible problem is the ceiling/floor effect. When the purchase intention in the non-TNA condition is high, it is difficult to improve the purchase intention using TNA technique. This high baseline purchase intention strongly depends on the magnitude of the bonus offer. If the bonus offer makes the net worth extremely attractive, the subjects would accept the deal despite the cognitive stress mentioned earlier, regardless of the technique used. The ceiling effect is first suggested by Mowen and Cialdini (1980) in the context of DITF. Therefore, we had to be careful about selecting the levels of the stimuli to detect the marginal effect of the TNA technique. The same argument applies to the unattractive conditions. If the initial offer is too unattractive (i.e., floor effect), the subjects would not accept the deal even after improving the deal with the second offer because the product has already been eliminated from their consideration set. It seems the results were not affected by the ceiling or floor effect because significant improvement in purchase intention was observed using TNA.

Not only do these findings contribute to the theoretical explanation of TNA technique, but they also have a strong marketing implication. Since average reservation price can be found using market research, the results suggest TNA should only be applied when the net worth of the whole deal is above the reservation price. If the net worth is lower than the reservation price, the whole deal is attractive and a bonus offer does not improve purchase rate. Since applying TNA technique often incurs additional costs, it is not justifiable to apply TNA when it does not improve the purchase rate. If TNA is to be employed, our findings can be used to determine the optimal value of the 
bonus offer. As found in the results, the second offer should not make the whole deal attractive to improve the purchase intention. Marketers can use this finding to estimate the maximum value of the price discount or bonus items to be used in a TNA setting.

\section{AUTHOR INFORMATION}

Dr. Yun-Oh Whang is an Assistant Professor of Marketing at John H. Sykes College of Business at The University of Tampa. He received his MBA from Washington University in St. Louis, and Ph.D. in Marketing from University of Southern California. He served as the CEO/President at Starlight Computing, Inc. and Senior Executive Vice President of Sales and Marketing at Sirius InnoTech, Inc. before coming back to Academia. E-mail: ywhang@ut.edu

\section{REFERENCES}

1. Brickman, P., D. Coates, and R. Janoff-Bulman (1978), "Lottery Winners and Accident Victims: Is Happiness Relative?" Journal of Personality and Social Psychology, 40, 492-500.

2. Burger, Jerry M. (1986), "Increasing Compliance by Improving the Deal: The That's-Not-All Technique," Journal of Personality and Social Psychology, 51 (2), 277-283.

3. Cialdini, Robert B. (1984), "Influence: How and why people agree to things," New York: New York.

4. ․ J. E. Vincent, S. K. Lewis, J. Catalan, D. Wheeler, and B. Darby (1975), "Reciprocal Concessions Procedure for Inducing Compliance: The Door-in-the-Face Technique," Journal of Personality and Social Psychology, 31, 206-215.

5. Dawar, N., and P. Parker (1994), “Marketing Universals: Consumers' Use of Brand Name, Price, Physical Appearance, and Retailer Reputation as Signals of Product Quality,” Journal of Marketing, 58, 81-95.

6. Dillard, James P. (1991), "The Current Status of Research on Sequential-Request Compliance Techniques," Personality and Social Psychology Bulletin, 17 (3), 283-288.

7. Fennis, Bob M. and Loes Janssen (2010), "Mindlessness Revisited: Sequential Request Techniques Foster Compliance by Draining Self-Control Resources," Current Psychology: A Journal for Diverse Perspectives on Diverse Psychological Issues, 29 (3), 235-246.

8. $\quad$ Fern, Edward F., Kent B. Monroe, and Ramon A. Avila (1986), "Effectiveness of Multiple Request Strategies: A Synthesis of Research Results,” Journal of Marketing Research, 23 (May), 144-152.

9. Freedman, Jonathan L. and Scott C. Fraser (1966), "Compliance Without Pressure: The Foot-in-the-Door Technique," Journal of Personality and Social Psychology, 4 (2), 195-202.

10. Gouldner, A. W. (1960), "The Norm of Reciprocity: A Preliminary Statement," American Sociological Review, 25, 161-178.

11. Helson, H. (1964), Adaptation-level Theory, New York: Harper \& Row.

12. Isen, A. M., and T. E. Shalker (1982), "The Effect of Feeling State on Evaluation of Positive, Neutral, and Negative Stimuli: When You Accentuate The Positive, Do You Eliminate The Negative?" Social Psychology Quarterly, 45, 58-63.

13. Kenrick D. T. and S. E. Gutierres (1980), "Contrast Effects and Judgments of Physical Attractiveness: When Beauty Becomes a Social Problem,” Journal of Personality and Social Psychology, 38, 131-140.

14. Manis, M. and J. C. Moore (1978), "Summarizing Controversial Messages: Retroactive Effects Due to Subsequent Information," Social Psychology, 41, 62-68.

15. Mowen, John C. and Robert B. Cialdini (1980), "On Implementing the Door-in-the-Face Compliance Techniques in a Business Context," Journal of Marketing Research, 17 (May), 253-258.

16. Pepitone, A. and M. DiNubile (1976), "Contrast Effects in Judgments of Crime Severity and the Punishment of Criminal Violators," Journal of Personality and Social Psychology, 33, 448-459.

17. Regan, D. T. (1971), "Effects of A Favor and Liking on Compliance," Journal of Experimental Social Psychology," 7, 627-639.

18. Sherif, M. and C. W. Sherif (1967), “Attitude as the Individual's own categories: The Social Judgmentinvolvement Approach to Attitude and Attitude Change," in C. W. Sherif and M. Sherif (Eds.), Attitude, Ego-involvement, and Change (pp. 105-139).

19. Tybout, Alice M. (1978), "Relative Effectiveness of Three Behavioral Influence Strategies as Supplements to Persuasion in a Marketing Context," Journal of Marketing Research, 15 (May), 229-242. 
NOTES 